\title{
The Current Evidence Base and Future Needs in Improving Children's Well-Being Across Europe: is There a Case for a Comparative Longitudinal Survey?
}

\author{
Haridhan Goswami ${ }^{1} \cdot$ Christopher Fox $^{1}$ • \\ Gary Pollock ${ }^{1}$
}

Accepted: 29 June 2015 / Published online: 10 July 2015

(C) Springer Science+Business Media Dordrecht 2015

\begin{abstract}
There has been a growing interest among academics, policy makers and practitioners in the subjective well-being of children and young people (CYP). The recognition of CYP's rights to having a good childhood and good future life chances, coupled with the injunction from the New Sociology of Childhood to consult with CYP as active agents have also resulted in an increasing interest in the use of well-being as a key concept in policy programmes in many countries. In recent years, child well-being has become a priority for the European political agenda. However, the main challenge for the European Union (EU) is to develop the best policies and approaches to effectively improve the well-being of children and young people using the most robust and suitable sources of data. This article identifies research gaps on children and young people's subjective well-being and discusses the policy relevance of longitudinal survey in the context of the EU strategy for CYP. It is argued that a longitudinal survey would fulfil research gaps and provide invaluable data for the European Union and its member states for monitoring and evaluation of existing policies on children and young people's well-being and developing future polices supported by robust data.
\end{abstract}

Keywords Well-being Children and young people $\cdot$ Longitudinal survey data Policy European Union · Comparative research

\section{Introduction}

Children's well-being is fundamental to that of society as a whole. Promoting children's well-being is not only vital in order for children to have a good childhood, but also as a

Haridhan Goswami

H.Goswami@mmu.ac.uk

1 Department of Sociology, Manchester Metropolitan University, Geoffrey Manton Building Rosamond Street West, Manchester M15 6LL, UK 
firm basis for their future well-being as adults (Rees et al. 2012). How children fare through critical points of development affects their quality of life, their productivity, welfare dependency and the transmission of their later life outcomes to their own children (Richardson 2012). In addition, the growing recognition of children and young people's rights for having a good childhood and good future life chances, coupled with the injunction from the New Sociology of Childhood (Prout and James 1997) to consult with children and young people (CYP) as active agents have resulted in an increasing number of studies on children and young people's well-being at national and international levels (Ben-Arieh 2005, 2006, 2008; Casas 2011; Bradshaw 2011). For a full review, see Richardson (2012); Ben-Arieh and Wintersberger (1997); and Ben-Arieh et al. (2001).

In recent years, child well-being has become a priority for the European political agenda. As part of the European cooperation on social protection and social inclusion, the European Union (EU) has expressed its strong political commitment to promoting well-being among children which is reflected (among others) in the establishment of an EU Task-Force on child poverty and child well-being in 2007 (TARKI Social Research Institute 2010). The on-going support and pledge of the EU on children's well-being is also evident from the recent 1.5 million Euros funding by the European Commission (under an FP7 call) for the Measuring Youth Well-Being (MYWEB) project that is assessing the feasibility of a European Longitudinal Study for Children and Young People. ${ }^{1}$ The aim of this article is to examine the research and policy relevance of a longitudinal survey to study CYP's well-being across EU member states. In the next section, we briefly review existing studies on CYP's well-being to identify research gaps that call for a new longitudinal research project. Then we review the EU's policy on children and young people in general and its emphasis for the member states to improve the well-being CYP in particular to highlight the importance of longitudinal data for the monitoring and evaluation of child and youth well-being policies. The final part of the article summarises the main findings and highlights some potential challenges on research with CYP that future research must take in this field.

\section{Review of Child and Youth Well-Being Studies: Exploring the Need for a New Longitudinal Study on Subjective Well-Being}

Research on CYP's well-being has made significant progress over the last decade. Therefore, the relevance of a new longitudinal study to children and young people's well-being needs to be evaluated in the context of scientific advancement in this area of research. Rees et al. (2010a) developed a typology to describe child and youth wellbeing studies. We adopt this typology to review three different approaches used in existing well-being studies:

\subsection{Social Indicators Movement}

Influenced by the wider social indicators movement, this approach initially focused on measurement and trends in child well-being primarily using 'survival indicators'

\footnotetext{
${ }^{1}$ For more information about this project, visit www.fp7-myweb.eu
} 
(Ben-Arieh 2008) such as rates of mortality, disease, and social problems affecting children (e.g., illiteracy, school failure). Major work informed by this approach includes the Child and Youth Well-being Index (Land et al. 2001) in the USA, the National Set of Child Well-being Indicators (Hanafin and Brooks 2005) in the Republic of Ireland, the Children and Young People's Well-being Monitor (Welsh Assembly Government 2008) for Wales, the Local Index of Child Well-being (Bradshaw et al. 2009) published by the Department for Communities and Local Government in England, Kids Count, a national and state-by-state effort to track the well-being of children in the US run by The Annie E. Casey Foundation (2012), OECD research on the comparison of child well-being across its 30 member countries (Chapple and Richardson 2009) and UNICEF publications (2007, 2010).

These indicator-based measures are useful to understand children and young people's well-being at the macro level. However, as Moore et al. (2014) argued, these macro indices predominantly focus on describing children's well-being at the expense of analysing the contexts that may contribute to or undermine their well-being. Using data from the 2007 US National Survey of Children's Health, Moore et al. (2014) developed micro-level indices (positive and negative) of child well-being by focusing on the three contextual domains of family, neighbourhood, and socio-demographic factors. Their indices significantly contributed to child well-being research as they clearly revealed how the independent variables (environment or context of children) play crucial roles in determining children's development and well-being.

While such indicators are important to begin to redress issues of inequalities and social exclusion that negatively affect children's health and wellbeing, they tend to ignore the potential, attributes and strengths of children. More specifically, this approach can be argued to treat children as 'passive agents not capable of evaluating their own lives'.

\subsection{Self-Report Surveys}

The second approach emphasises measuring child well-being through self-report surveys. A number of instruments have been developed over the last decade to measure young people's own assessment of their lives. One of the most widely used is Huebner's Multi-Dimensional Student Life Satisfaction Scale (Huebner 1994) which measures well-being in five domains - family, friends, school, living environment, and self. Similarly, Cummins and Lau (2005) in their work with children and young people in Australia have developed a Personal Well-being Index covering the domains of standard of living, personal health, achievement in life, personal relationships, personal safety, feeling part of the community, and future security.

The international Health Behaviour in School-aged Children survey covers a number of key areas of young people's health and well-being. It has developed from an initial survey in five countries (including England) in 1983/4 to 43 countries involved in the latest wave of the survey in 2009/10. In the UK, several waves of the Tellus survey (Ofsted/DCSF) have surveyed young people about their well-being and views under the five themes of the Every Child Matters framework - Be Healthy, Stay Safe, Enjoy and Achieve, Make a Positive Contribution, and Achieve Economic Well-being. The survey questionnaire included some questions about happiness and about relationships with family and friends. 
In addition, some large social surveys have begun to incorporate self-report instruments for young people. Understanding Society, previously known as The British Household Panel Survey, has a youth questionnaire for young people aged 11 to 15 about their happiness, feeling troubled and self-esteem. Outside of UK, the Danish Longitudinal Survey of Children, the Youth component of the German SocioEconomic Panel (SOEP), French Longitudinal Survey of Children, Swiss Survey of Children and Youth, the European Social Survey and the European Quality of Life Survey and some cross-sectional surveys (eg, Progress in International Reading Literacy Study, Progress for International Student Assessment, Trends in International mathematics Science Study, the European School Project on Alcohol and other Drugs) included some questions on well-being and its various domains for young people in various age groups. For a full review of these surveys, see Richardson (2012); Gabos and Kopasz (2013) and Gabos and Toth (2011).

The main advantage of this approach is that it focuses on self-reported well-being. More specifically, the international surveys among children and young people provide precious comparable data on child well-being covering countries in the EU and beyond. For example, the Organisation for Economic Co-operation and Development (OECD) conducted a comparative analysis on child well-being that provides useful insights on the state of child well-being among 30 OECD countries by focusing on six well-being domains: material well-being; housing and environment; education; health; risk behaviours; and quality of school life (OECD 2009). Moreover, household panel surveys (eg Understanding Society) provide new opportunities to explore the effect of changes in young people's lives on their overall well-being. However, the concepts and domains of well-being used in this work were developed primarily from concepts which originated from the study of adult well-being. Fattore et al. (2007) argue that these concepts are not directly transferable to the measurement of the well-being of children and young people. Moreover, as Bradshaw (2009) argues, most of these studies include only a limited number of well-being domains and therefore do not provide the full picture on the state of well-being for children and young people. These limitations influence the development of the third approach: child and young people centric studies.

\subsection{Children and Young People Centric Well-Being Studies}

The third approach focuses on developing concepts and frameworks which incorporate children's perspectives. This strand is still at a relatively early stage, but there are a small number of examples of attempts to develop well-being frameworks from children's perspectives. Consultation exercises with children and young people in the Republic of Ireland (Gabhainn and Sixsmith 2005; Hanafin et al. 2007) and Australia (Fattore et al. 2007) have identified important differences in children and young people's ideas about well-being.

In this regard, the first large-scale project took place in the UK in 2005, undertaken by The Children's Society when it included open-ended questions asking young people about their views on well-being and the factors which promoted and hindered it in its national survey of 11,000 young people aged 14 to 16 . The thematic and content-based analyses of these responses identified ten key areas (The Children's Society 2006). These were, roughly in order of their frequency of occurrence in the responses (1) family, (2) friends, (3) leisure, (4) school, education and learning, (5) behaviour, (6) the 
local environment, (7) community, (8) money, (9) attitudes, and (10) health. Following this child-centric approach, Rees et al. (2010b) developed an index of children's subjective well-being in England. This ten-domain Index includes young people's satisfaction on family or carer, friends, health, appearance, time use, future, home, money and possessions, school, and amount of choice.

A number of similar initiatives are also observed in the mainland European countries. For example, the Danish Youth Survey 2002 (Helweg-Larsen et al. 2004) examined young people's experiences and views on six themes including family, school, leisure and social networks, health and health behaviour, sexual experiences with peers and adults and violence in immediate surroundings. The DJI Youth Survey in Germany explores adolescents' trust in social institutions, their political attitudes, interest in politics, value orientation as well as their willingness regarding political activity (DJI 2000).

This third approach has been taken further by an international group of researchers linked to Children's Worlds, the International Survey of Children's Well-Being (ISCWeB). The study aims to collect solid and representative data on children's lives and daily activities, their time use and in particular their own perceptions and evaluations of their well-being. Each of the 14 participating countries around the world collected data from a sample of 3000 children aged 8 to 12 in the first wave of the survey in 2012. The second wave of the survey covering almost 45,000 children from 15 countries across four continents is underway. The results of this project are only now being disseminated. For some initial findings of this project, see Rees and Dinisman (2014); Montserrat et al. (2014); Sarriera et al. (2014).

Having the unique position of 'research with and by children', this third approach reflects a major paradigm shift in child well-being research (Mason and Danby 2011). Thus, the importance of including children as active agents whose perspectives are heard in matters concerning them especially in child well-being policies is gaining momentum within child indicator research. However, child well-being researchers (eg Richardson 2012; Bradshaw 2009; Casas 2011) are increasingly concerned about the shortage of internationally comparable subjective data on children's and adolescents' perceptions, evaluations and aspirations which they consider useful for decisionmaking and evaluating social change.

In this regard, the data from the ISCWeB by the Children's World (2012) would supply invaluable comparative data on subjective well-being among a number of EU member states and countries beyond Europe. Several waves of data from these countries would also help researchers to examine change over time at the cohort or aggregate level. However, as Howieson et al. (2008) argued, such data appear to have lacking on detecting change at the individual level. Therefore, they do not enable an understanding of an individual's transition through different activities and statuses that might be linked to their subjective well-being. Since childhood is not static but dynamic, a holistic view taking into account both changes at different stages of children and young people's development and transitions is required. This explains why there is a growing belief that in order to better understand how these changes and other socio-economic factors related to these changes affect children's and young people's well-being a longitudinal survey using a 'children and young people centric approach', may be required. Having discussed the relevance of a longitudinal survey in the context of wider scientific 
development on child well-being research, we now discuss the significance of such a study in the context of EU policies on children and young people.

\section{EU Policy on Children and Young People and Their Well-Being: the Potential Value of a Longitudinal Study for Monitoring and Evaluation}

The EU, today, is experiencing major economic, environmental, political and social changes that directly affect children and young people. Children in the EU face a higher risk of relative poverty than the population as a whole (20\% for children aged $0-15$ and $21 \%$ for those aged 16-24, compared to $16 \%$ for adults) (Commission of the European Communities 2006). Moreover, the percentage of children living in poverty or social exclusion is on the rise in a number of Member States as a result of the impact of the economic crisis (Council of the European Union 2012). Demographic changes, for example higher life expectancy and lower fertility rates together with changing gender roles (and related to this, increased participation of women in the labour force) are factors that influence the family context in which children grow up. New challenges arise due to higher mobility demands of the labour market, which may complicate and reduce the possibility and the frequency of intergenerational familial contacts. New family structures have arisen as a result of increase in divorce rates; single families, stepfamilies, and patchwork families. In addition, more and more children are growing up in migrant families throughout European countries (Perrig-Chiello 2009).

The EU has long recognised the necessity of specific interventions to address children and young people's needs, and thus of complementing interventions targeted at the whole population with intervention focused on children. In particular, various complementary initiatives have been developed since 2000 in the framework of the Open Method of Coordination on Social Protection and Social Inclusion (Social Protection Committee 2012). For a full review of these policies, see Gabos and Kopasz (2013); Gabos and Toth (2011).

Member States have addressed the issue in the context of their National Action Plans on Social Inclusion (and subsequently National Strategic Reports on Social Protection and Social Inclusion) and have seen their policies regularly monitored through the Annual Joint Report adopted by the Commission and the Council. This included a thorough monitoring exercise in the 2008 Joint Report.

Through the PROGRESS programme (EC 2006), the EU has supported numerous studies and peer reviews on the issue as well as relevant stakeholder networks (such as Eurochild and Confederation of Family Organisations in the European Union) and transnational projects (eg European Cities Against Child Poverty). Specific focus was put on strengthening existing analytical tools. This implied in the first instance reinforcing the child dimension of the existing social inclusion indicators' portfolio (eg by having more detailed age breakdowns of the at-risk-of-poverty rate for children, by refining the material deprivation and low work intensity indicators). In 2007, the EU Task-Force on Child Poverty and Child Well-Being was established by the EU Social Protection Committee (SPC). The EU Task-Force went on in 2008 to produce a report (EU Task-Force 2008) spelling out recommendations for analysing, monitoring and assessing child poverty and well-being at EU, national and sub-national levels. The Task-Force report, together with its recommendations, was formally endorsed by the 
SPC and the European Commission and is now part of the EU acquis (Social Protection Committee 2012).

Although EU Cooperation on social issues (in particular through the Social OMC) has provided the main framework for addressing child poverty and child well-being in an EU context, many other policies have touched upon the issue: education and training policies (in particular in relation to early school leaving, early childhood education); the EU Agenda on the Rights of the Child; reconciliation, work and family policy (among others in the framework of the European Alliance for Families); health policy, cohesion policy (through the development of childcare and/or housing infrastructures and support for deinstitutionalisation) (Social Protection Committee 2012).

The Europe 2020 Strategy gives a new impetus to efforts addressing child poverty and social exclusion in the EU. A number of Member States have set specific targets or sub-targets relating to child poverty/social exclusion as their contribution to the headline European target to reduce the number of people at risk of poverty and social exclusion by at least 20 million by 2020 (Council of the European Union 2012). Therefore, Euro 2020 has given priority to fighting poverty and social exclusion and improving the well-being of children and young people.

In the context of these European policies, a comparative longitudinal survey of child wellbeing offers policy-makers at a European and Member State level a number of new possibilities for policy formulation. Longitudinal well-being surveys can help us understand transitions in young peoples' lives (for instance the step from education to the labour market), interruptions and trauma (break up the family unit) as well as turning points that might contribute to the understanding of well-being. In this regard, Howieson et al. (2008) argue that transitions are inherently a longitudinal process and so longitudinal data are necessary to analyse and understand the transitions of individuals over time and answer questions about the impact of policy interventions on young people's outcomes.

Longitudinal well-being surveys also allow for the measure of stability or instability and the identification of causal relationships. Individual-level change can only be understood in the context of changes taking place over a considerable amount of time. This type of analysis enables researchers to identify patterns of change (e.g., steady growth, fluctuation around a low level, sudden decline followed by stability) (Lynn 2009). For example, if the proportion of children and young people satisfied with their life is relatively stable over time there might be many of them starting to feel satisfied with their lives while others are not satisfied anymore. A small proportion of children and young people might be satisfied with their lives on a continuous basis, while the majority show strong variations in time. This insight provides greater information about the dynamics and the factors associated with children and young people being satisfied with their lives.

Longitudinal studies can be viewed as a form of quasi-experimental evaluation design (ISER 2002). They involve the construction of a 'time series', which, in some contexts provides an evaluation design able to withstand some of the key threats to internal validity that 'quasi-experimental' evaluations are designed (Cook and Campbell 1979). As compared to the use of administrative data, a key advantage of longitudinal survey data is the potential to overcome the threat of 'instrumentation'. If a time series is constructed using administrative data there is a risk that changes to the way the variable is defined or the way the data is 
collected will undermine the internal validity of the design (Shadish et al. 2002). However, in a survey, where consistent survey instruments are used, this threat posed by inconsistent instrumentation is avoided. As ISER (2002) note, we can at least say with certainty from the statistical analysis of biographies what events preceded others, even though we still have problems in deciding which event in relation to another event was the underlying cause.

This application of longitudinal data for establishing causal relationships is evident in policy evaluation where the success of policies on returns to qualifications and education are more generally understood using birth cohort survey data (ISER 2002). In this regard, outcomes in adulthood such as occupation and earnings are set against qualifications, taking account of ability as tested in childhood and numerous other circumstances and experiences earlier in life that might be confounded with them. ISER (2002) concludes that "Statistical modeling of this kind, is not a perfect substitute for the controls offered in randomized experiments, but goes some of the way to producing the most plausible accounts of micro economic processes." For more examples of programme evaluation using longitudinal quasi-experimental design, see Esbensen et al. 2001; Humphrey et al. 2010).

While insights from longitudinal surveys have much to offer to policy it is worth noting that different designs will be associated with answering different research and policy questions. Birth cohort studies allow researchers to chart the development of the human life course. As ISER (2002) notes, the data collected for any single birth cohort confounds age, period and cohort effects at any particular point in time. In addition, comparison of more than one cohort enables the researcher to hold constant one of these three 'extrinsic' factors, for example, comparing cohorts at a given age to establish a cohort effect or cohorts at the same age at different times to establish a period effect. The data can then be used prospectively to make predictions about the outcomes of particular circumstances and experiences in life occurring at particular points in time or retrospectively to identify the circumstances and experiences in earlier life that underpin a given outcome later (ISER 2002).

Household panel surveys sample the whole population rather than single years of age with the aim of understanding the dynamics of change of the whole population, and its evolution over the lifetime of the study (ISER 2002). These surveys usually follow all the people living in the sample household, not just a reference individual. The origin of household panel studies was in the need to explore the dynamics of poverty and income and an understanding that these could not be explored through separate snapshots, but rather required an approach to collecting a continuous record about income in particular. However, the household panel survey is also particularly suited to the analysis of the dynamics of household formation and dissolution, and associated events and outcomes (ISER 2002).

In a briefing In Praise of Panel Surveys, Berthoud and Burton (2008) bring together a number of case studies that demonstrate the impact findings from longitudinal surveys (specifically panel surveys) can have on policy. For example, Jenkins (2008) recounts how, in the 1990s inequality and poverty rates flattened off and it appeared that there was little or no change in the income distribution from 1 year to the next. However, the British Household Panel Survey revealed that apparent cross-sectional stability hid longitudinal flux - households' incomes fluctuate between 1 year and the next, and there was substantial turnover in the membership of the low-income 
population. Jenkins goes on to demonstrate how these findings influenced policy including much of the emphasis in the Labour government's welfare reforms from the late 1990s that reflected a dynamic perspective with a focus on moving people into work and making work pay. Ermisch (2008) demonstrates how longitudinal data has helped researchers and policy-makers better understand family dynamics. Thus, in $1975,9 \%$ of births in Britain were outside marriage and by 2006, this had risen to $44 \%$. However, three-quarters of births outside marriage are jointly registered by both parents and mostly to parents living at the same address. It therefore appeared that just over a quarter of recent births were in cohabiting unions. The question raised was therefore 'does this mean that the rise in extra-marital births should be less cause for concern?' Ermisch demonstrates how longitudinal data from the British Household Panel Survey showed that the duration of cohabiting relationships was shorter than married partnerships and that women from failed cohabiting partnerships took a relatively long time to find another live-in partner. Moreover, in a recent article Bradshaw (2014) has provided empirical evidence on the association between child subjective well-being and social policy from a number of national and international surveys.

This overview of EU policies for children and childhood and illustrations of how longitudinal survey data can support policy making suggests that while EU policies have evolved over the years incorporating other domains of well-being such as education, family, employment, and health the collection of longitudinal data is likely to result in new insights into micro or child level changes and their impact on overall and domain specific well-being within and across its member states. In addition, these data will offer tools for monitoring progress over time at the aggregate or country level. These data will be useful to assess the impact of relevant policies (at EU and country levels) on the situation of children and, thereby, directly contributing to achieving the Europe 2020 objectives of smart, sustainable and inclusive growth.

\section{The Case for a New Longitudinal Survey on Children's and Young People's Subjective Well-Being in the EU}

The objective of this article was to examine the research and policy relevance for a longitudinal survey among children's and young people's (CYP) well-being across the EU member states. We reviewed existing major studies on CYP's well-being to identify research gaps that call for a new longitudinal research project. Then we examined the policies of the EU on children and young people in general and its emphasis on the member states to improve the well-being CYP in particular to highlight the importance of longitudinal data for monitoring and evaluation of child and youth well-being policies.

Our review of literature suggests a gradual shift in the research with children and young people's well-being. To summarise, influenced by the 'developmental perspective' and wider social indicators movement, the first strand of research has focused on measurement and trends in child well-being primarily using available indicators such as child poverty rates, child injuries, educational attainment, and so on. While such indicators are important to begin to redress issues of inequalities and social exclusion which negatively impact on children's health and wellbeing, they tend to ignore the 
potential, attributes and strengths of children. This strand is also being accused of treating children as 'passive agents - not capable of evaluating their own lives' by the proponent of the second strand of 'self-report' based research on children and young people's well-being. Whilst the second strand including some major longitudinal surveys such as Understanding Society collected data directly from children and young people, the concepts and limited number of well-being domains used in this work were developed primarily from concepts which originated from the study of adult wellbeing. This adult-centric approach in child well-being research appears to be problematic as it ignores children's perspective in developing well-being framework. The growing recognition of children and young people's rights for having a good childhood and good future life chances, coupled with the injunction from the New Sociology of Childhood to consult with children and young people as active agents have influenced the third strand which has focused on developing concepts and frameworks of wellbeing by incorporating children's perspectives. In addition to developing a well-being framework identified by children and young people, this approach more focuses on the subjective measures in well-being research. Although the third strand (children and young people centric approach) indicates a paradigm shift in research with CYP's wellbeing, surveys conducted so far under this strand including those conducted in a single country or multiple countries for cross-country comparison appears to be predominantly cross-sectional.

In the context of this scientific advancement on child well-being research, we recognise the strength of subjective measures of well-being from those crosssectional surveys for policy evaluation and cross-cultural comparison at the aggregate level. However, childhood is not static but dynamic. Therefore, a holistic approach by taking into account both changes at different stages of children and young people's development and transitions can further help developing our existing knowledge and understanding of child well-being. Therefore, to supplement findings of the latest crosssectional surveys on CYP's subjective well-being undertaken by Children's World (2012) under its ISCWeB project and to better understand how changes in different phases of childhood and/or the socio-economic factors related to these changes affect child well-being, a robust new longitudinal survey by adopting a child and young person centric approach is required.

Our review of EU policies for children and childhood identifies the economic aspect of well-being to be dominant in the EU policies for children and young people. However, a major shift on EU policies happened in 2007 through the establishment of EU Task-Force on Child Poverty and Child Well-Being under the EU Social Protection Committee. In this regard, EU's policies incorporating other domains of well-being specially education, family, employment, and health got momentum in 2008 when the EU Task-Force produced a report (EU Task-Force 2008) spelling out recommendations for analysing, monitoring and assessing child poverty and well-being at EU, national and sub-national levels. This commitment from the EU is also reflected in its Europe 2020 Strategy which gives a new impetus to efforts addressing child poverty and social exclusion and improving the well-being of children and young people. The EU, therefore, has made major improvement in its policies for children and young people by emphasising on not only economic aspects but also other domains of well-being. Nevertheless, it is still a major challenge for the EU to effectively evaluate and develop the best 
policies for child and youth well-being by taking into account the views of those affected by these policies. We argue that for systematically measuring changes in child subjective well-being within and across its member states, monitoring progress over time and introducing new policies supported by reliable data, the EU requires a 'children and young people centric' longitudinal survey covering it member states. The robust data from such survey would also directly contribute to achieving the Europe 2020 objectives of smart, sustainable and inclusive growth by providing evidence.

\section{Conclusion}

While a longitudinal survey on CYP's subjective well-being offers the best approach to understanding young people's transitions and collecting robust data for evaluating child well-being policies at the EU and its member state level, it poses several challenges. Some of these challenges are generic to all longitudinal studies e.g., design issues, sampling, sample size, measurements (panel conditioning, measurement error), and data collection (modes of data collection, refusal, attrition). In addition, variability exists among European nations on a number of factors including availability and coverage of sampling frames, laws and regulations that restrict aspects of survey practice, availability and abilities of survey research organisations, cultural and behavioural norms, language (s) spoken, geographical dispersal of the study populations (Lynn 2003). In this regard, major cross-national surveys in Europe (eg European Social Survey, Eurostat, Eurobarometer, European Values Study) and other regions (eg Afrobarometer, Latinobarometer, World Values Surveys, and International Social Survey Programme) might provide useful insights to deal with these factors in producing comparable data. Although it is not the remit of this paper to discuss these challenges in detail, future studies must consider the following aspects carefully for a robust longitudinal survey on children's and young people's well-being in EU member states:

Firstly, on conceptual level, there are debates on whether to use 'hedonic' or 'eudaimonic' approach in defining CYP's well-being. Scholars influenced by the hedonic approach (eg Diener and Lucas 1999) view well-being in terms of subjective happiness and the experience of pleasure versus displeasure broadly construed to include all judgements about the good/bad elements of life. On the other hand, the eudaimonic approach maintains that not all desires-not all outcomes that a person might value -would yield well-being when achieved (Ryan and Deci 2001). It focuses on meaning and self-realisation and defines well-being in terms of the degree to which a person is fully functioning. Ryff and Singer $(1998,2000)$ have explored the question of well-being in the context of developing a lifespan theory of human flourishing. Ryff and Keyes (1995) spoke of psychological well-being (PWB) as distinct from subjective well-being and presented a multidimensional approach to the measurement of PWB that taps six distinct aspects of human actualization: autonomy, personal growth, self-acceptance, life purpose, mastery, and positive relatedness.

The recent theoretical and conceptual development on well-being (Compton et al. 1996; King and Napa 1998; McGregor and Little 1998; Proctor et al. 2009) 
suggests that any future study on well-being needs to examine the potential for using a holistic approach focusing on both hedonic and eudaimonic aspects. However, Rees et al. (2013) argue that the affective aspect of well-being is less stable over time because of its reliance on people's experience of positive and negative emotions, which typically varies over time. However, people's evaluations of their overall (life satisfaction) or particular aspects of their life (domain satisfaction) are thought to be more stable over time. A potential advantage of a longitudinal survey is its ability to capture both these stabilities and instabilities over time, allowing policy-makers to consider how policy interventions need to be tailored to the life course.

Secondly, on measurement level, we also find debates between 'objective' vs. 'subjective' measures of well-being. Objective measures of social reality are those which are not filtered by perceptions and are independent from personal evaluations. On the other hand, subjective measures are supposed to explicitly express subjective states, such as perceptions, assessments and preferences for example (Noll 2013). Although objective measures provide useful information on wellbeing at the macro-level, there are criticisms and caveats to be taken into account when confronting such measures (McGillivray 2007). For example, Hicks (2011) terms the approach to using objective well-being measures as 'paternalistic'. In order to explain the usefulness of subjective measures in well-being research, Kroll and Delhey (2013) used the famous Thomas theorem (Thomas and Thomas 1928: 572) grounded in Symbolic Interactionism: 'If men (people) define situations as real, they are real in their consequences.' Thus, the subjective measures draw on human perception and place the individual themselves to decide what is crucial in assessing their lives. In spite of some methodological issues such as the problems of measurement, bias, and divergence (see Veenhoven 2002), they provide important additional information over and above objective measures on the quality of people's lives (Hicks 2011). In this regard, Ben-Arieh (2005) emphasised on the normative argument saying that child well-being researchers have a moral obligation to listen to children and take seriously what they think and feel. To put forward the case for subjective measures of well-being, Bradshaw (2014) pointed out United Nations Convention on the Rights of the Child, which provides a legal framework obliging almost all countries in the world to listen to children and take their views into account. Future research on longitudinal survey on CYP's wellbeing needs to emphasise more on the subjective measures of wellbeing for the normative and legal responsibilities and their policy relevance discussed in this paper.

Thirdly, there are a number of models of how the children and young people can/ should be involved in a study. Shaw et al. (2011) identified four models and discussed them with their unique features. The models are (1) CYPs are sources of research data, (2) CYPs are consulted about the research, (3) CYPs are collaborators in the study, and (4) CYPs have ownership of the research. There is an order among the models in terms of the degree of control and participation that the CYP may have in a study - from the lowest level in model 1 to the highest level in model 4. The level of their participation (whether just as respondents, consultants, collaborators or owners) will guide how the whole study needs to be designed and resource allocated. This issue needs to be settled based on a range of factors 
including length and depth of study, availability of resources, and the preferences of the CYP concerned.

Fourthly, choosing an appropriate research method that is meaningful and accessible for the children and young people in the study is also a major challenge for a longitudinal survey in the EU. The UN Committee on the Rights of the Child has identified a number of groups of children and young people as being amongst the least likely to be able to access their rights (Shaw et al. 2011). These groups include those who are (a) very young, (b) young parents, (c) 16-18 year olds, (d) black and minority ethnic, (e) disabled, (f) in public care, (g) refugees and asylum seekers, (h) in trouble with the law, (i) living in poverty, (j) affected by violence, abuse and neglect, (k) lesbian, gay, bisexual and transgender, (l) travellers. To be successful, the longitudinal survey in the EU needs to ensure that the chosen method or sampling strategy does not systematically exclude children and young people from these or other (eg, young runaways) groups for participating in the study.

Fifthly, the age of the children that a quantitative longitudinal survey wishes to recruit as respondents will have a major impact on the chosen method and designing of research tools. There is empirical evidence on the impact of age groups on the length and contents of the survey questionnaire. For example, after conducting pilot and cognitive tests among children in both Primary and Secondary Schools in England, Rees et al. (2010a, 2012) observed that long questionnaire and some multiple- item scales on well-being and its domains are not suitable for the young people in Primary School because of their short attention span and cognitive ability. In addition, some domains (eg relations with parents) appeared to have lower impact on the over-all subjective well-being for the older group of young people.

Sixthly, working with children and young people who have special needs or vulnerability will require careful thought. Researchers must decide whether to be flexible in choosing modes so that needs of the children and young people are met which allows room for mode effect in the study or to apply strictly an unified mode of data collection disregarding the needs to the respondents.

Seventhly, the majority of ethical issues that apply to adults may also apply to children, though there are some additional specific concerns that arise in research with children and young people. For example, since there is an inherent power relationship between adult researchers and children, the issue of consent becomes more complex. Obtaining informed consent from children (and their parents and carers) to participate in a longitudinal research has additional feature as consent may require from children to all of the following: (a) consent to participate in the study in principle (and to continue, in principle), (b) consent at the start of each data collection episode, (c) ongoing consent throughout specific data collection episodes (eg to continue with an interview or focus group), and (d) consent to use data. Working with young people is becoming increasingly tightly regulated. Moreover, there may be different child protection policies in member states in the EU. For example, everybody working directly with young people in the England and Wales requires to have enhanced Disclosure and Barring Services (DBS) check. For conducting a common longitudinal survey on children and young people's subjective well-being in Europe, special attention to child protection policy and a detail plan after assessing all possible risks are required. 
Eighthly, because of the personnel costs, the techniques needed to maintain contact with children and young people over time, the costs of incentives, and the need for detailed documentation of data, the time and funding required for longitudinal studies are much greater than those required for cross-sectional designs. Therefore, continuity of funding, maintaining stability in work by recruiting full-time permanent staff and helping them to uphold their morale throughout the lifetime of the project are crucial for the success of a common longitudinal survey on CYP's subjective well-being in Europe.

Ninthly, since childhood is influenced by a range of socio-economic, cultural, and psychological factors, longitudinal study on child well-being in Europe requires experts from multiple disciplines including sociology, economics, education, psychology, childhood studies. In addition to providing diverse theoretical approaches to improve our understandings on children's well-being, they can identify and propose suitable measures for a range of potential factors such as family structure, resources in home, relationship between family members, neighbourhood support and safety, family income, parental education that enhance or hinder children's development and well-being (Moore et al. 2014). In this regard, a clear theoretical framework that distinguishes between independent variables (environmental or contextual factors) and dependent variable (child well-being) is crucial for robust data and empirically derived child well-being policies.

Finally, although this article primarily focuses on quantitative survey data, qualitative longitudinal study can provide valuable data to supplement the findings of quantitative data. Therefore, a feasibility study can be carried out to assess even for a small-scale qualitative longitudinal study on children and young people wellbeing in each member state in Europe. Apart from ensuring methodological rigor, qualitative and quantitative data on child well-being generated by this mixed method will be crucial for evaluating the effectiveness EU policies on child well-being.

To summarise, the lack of comparative data sets in the EU collected systematically over time on subjective well-being which is defined on solid theoretical and conceptual grounds by taking into account the views of children and young people calls for a new longitudinal survey. In addition to fulfilling the research gaps, such dataset will be invaluable for the European Union and its member states for monitoring and evaluation of existing policies on children and young people's well-being and developing future polices supported by robust data. A common longitudinal survey on children's and young people's subjective well-being in the EU will involve significant cost. Although the EU has expressed its initial interest in such surveys, evident from its recent 1.5 million Euros funding for assessing the feasibility of a European Longitudinal Study for Children and Young People (see MYWEB 2014), execution of such a large-scale project will require long-term financial commitments from both the European Commission and EU member states. Moreover, even after starting such a survey it will take several years to generate data which is longitudinally comparable at the individual level. Therefore, in the meantime, attempts should be made to provide better access to existing cross-sectional (e.g., Health Behaviour in School-Aged Children, International Survey of Children's Well-Being) and longitudinal surveys (e.g., 
Understanding Society, the Youth component of the German Socio-Economic Panel) in the EU and non-EU countries and improve these surveys to capture better quality data on children's and young people's lives.

Acknowledgments We would like to thank two anonymous reviewers for their helpful comments and suggestions. This article is prepared from the MYWEBresearch project (http://fp7-myweb.eu/), which has received funding from the European Union's Seventh Framework Programme for research, technological development and demonstration under the grant agreement no 613368. The views presented in the paper are solely the authors and do not necessarily reflect those of the Commission.

\section{References}

Annie E. Casey Foundation (2012). Kids count. http://www.aecf.org/MajorInitiatives/KIDSCOUNT.aspx. Accessed 7 Nov 2012.

Ben-Arieh, A. (2005). Where are the children? Children's role in measuring and monitoring their well-being. Social Indicators Research, 74, 573-596.

Ben-Arieh, A. (2006). Is the study of the "State of Our Children" changing? Revisiting after five years. Children and Youth Services Review, 28(7), 799-811.

Ben-Arieh, A. (2008). The child indicators movement: past, present and future. Child Indicators Research, 1, $3-16$.

Ben-Arieh, A., \& Wintersberger, H. (Eds.). (1997). Monitoring and measuring the state of the children: Beyond survival. Eurosocial Report, 62. Viena: European Centre for Socal Welfare Policy and Research.

Ben-Arieh, A., Kaufman, N. H., Andrews, B. A., Goerge, R., Lee, B. J., \& Aber, J. L. (2001). Measuring and monitoring children's well-being. The Netherlands: Kluwer.

Berthoud, R., \& Burton, J. (2008). In Praise of panel surveys (pp. 2-3). Colchester: University of Essex.

Bradshaw, J. (2009). Social inclusion and child poverty. In P. Perrig-Chiello (Ed.), Interdisciplinary Workshop Report on Changing childhood in a changing Europe. ESF Social Sciences Unit: Strasbourg.

Bradshaw, J. (2011). The well-being of children in the United Kingdom. Bristol: Policy Press.

Bradshaw, J. (2014). Subjective well-being and social policy: Can nations make their children happier? Child Indicators Research, Online Frist. http://link.springer.com/article/10.1007\%2Fs12187-014-9283-1.

Bradshaw, J., Bloor, K., Huby, M., Rhodes, D., Sinclair, I., Gibbs, I., Nobel, M., McLennan, D., \& Wilkinson, K. (2009). Local index of child well-being: Summary report. London: Department for Communities and Local Government.

Casas, F. (2011). Subjective social indicators and child and adolescent well-being. Child Indicators Research, $4,555-575$.

Chapple, S., \& Richardson, D. (2009). Doing better for children. Paris: OECD Publishing.

Children's World (2012). International Survey of Children's Well-Being (ISCWeB). http://childrensworlds.org/home. Accessed 7 Nov 2012.

Commission of the European Communities (2006). Towards an EU strategy on the rights of the child. Communication from the commission. Commission of the European Communities: Brussels. http://ec.europa. eu/anti-trafficking/download.action; jsessionid=gBHfQ1SN4TcK4vKZCJ9Q $\mathrm{xVlp} 41 \mathrm{cpHy} 2 \mathrm{~h}$ Mh13pNkynhsPJYdSGqkt!-1841744785?nodeId=de3e25e9-b2c5-45e2-a4a8-926554141d66\&fileName= COM+2006+367+Strategy+on+the+Rights+of+the+Child_en.pdf\&fileType-pdf.

Compton, W. C., Smith, M. L., Cornish, K. A., \& Qualls, D. L. (1996). Factor structure of mental health measures. Journal of Personality and Social Psychology, 71, 406-413.

Cook, T., \& Campbell, D. (1979). Quasi-experimental design and analysis issues for field settings. Boston: Houghton Mifflin Company.

Council of the European Union. (2012). Preventing and tackling child poverty and social exclusion and promoting children's well-being. Brussels: Council of the European Union. http://register.consilium. europa.eu/pdf/en/12/st14/st14437.en12.pdf.

Cummins, R., \& Lau, A. (2005). Personal wellbeing index - School children (3rd ed.). Melbourne: School of Psychology, Deakin University.

Deutsches Jugendinstitut (DJI), München (2000). DJI-Jugendsurvey 2000. GESIS Datenarchiv, Köln. ZA3609 Datenfile Version 1.0.0. doi:10.4232/1.3609. 
Diener, E., \& Lucas, R. E. (1999). Personality and subjective well-being. In D. Kahneman, E. Diener, \& N. Schwarz (Eds.), Well-being: The foundations of hedonic psychology (pp. 213-229). New York: Russell Sage Found.

Ermisch, J. (2008). Births outside marriage: The real story. In R. Berthoud \& J. Burton (Eds.), Praise of panel surveys (pp. 8-9). Colchester: University of Essex.

Esbensen, F.-A., Osgood, D. W., Taylor, T. J., Peterson, D., \& Freng, A. (2001). How great is G.R.E.A.T? Results from a longitudinal quasi-experimental design. Criminology and Public Policy, 1(1), 87-118.

EU Task-Force. (2008). Child poverty and well-being in the EU current status and way forward. Luxembourg: Office for Official Publications of the European Communities.

European Commission. (2006). Decision No 1672/2006/EC of the European Parliament and of the Council of 24 October 2006 establishing a Community Programme for Employment and Social Solidarity Progress. Brussels: EC.

Fattore, T., Mason, J., \& Watson, E. (2007). Children's conceptualisation(s) of their well-being. Social Indicators Research, 80, 5-29.

Gabhainn, S., \& Sixsmith, J. (2005). Children's understandings of well-being. Dublin: National Children's Office.

Gabos, A., \& Kopasz, M. (2013).Conception paper for an Integrated Poverty and Living Condition Indicator System (IPOLIS) database. In GRID/TARKI Expert Workshop on 'Framework and methods for indicators building for various vulnerable groups.' Budapest, 27-29 November.

Gabos, A., \& Toth, I. G. (2011). Child well-being in the European Union: Better monitoring instruments for better policies. Budapest: TARKI Social Research Institute.

Hanafin, S., \& Brooks, A. M. (2005). Report on the development of a national set of child well-being indicators. Dublin: National Children's Office / The Stationery Office.

Hanafin, S., Brooks, A. M., Carroll, E., Fitzgerald, E., Gabhainn, S. N., \& Sixsmith, J. (2007). Achieving consensus in developing a national set of child well-being indicators. Social Indicators Research, 80, 79104.

Helweg-Larsen, K., Sundaram, V., Curtis, T., \& Larsen, H. V. (2004). The Danish Youth Survey 2002: asking young people about sensitive issues. International Journal of Circumpolar Health, 63(2), 147-152.

Hicks, S. (2011). The measurement of subjective well-being. Paper for Measuring National Well-Being Technical Advisory Group. Newport: ONS: http:/www.ons.gov.uk/ons/guide-method/user-guidance/ well-being/about-the-programme/advisory-groups/well-being-technical-advisory-group/themeasurement-of-subjective-well-being.pdf. Accessed 11 Mar 2014.

Howieson, C., Croxford, L., \& Howat, N. (2008). Meeting the needs for longitudinal data on youth transitions in Scotland - An options appraisal. Edinburgh: Scottish Government Social Research.

Huebner, E. S. (1994). Preliminary development and validation of a multidimensional life satisfaction scale for children. Psychological Assessment, 6(2), 149-158.

Humphrey, N., Lendrum, A., \& Wigelsworth, M. (2010). Social and Emotional Aspects of Learning (SEAL) Programme in Secondary Schools: National Evaluation. Research Report No. DEF-RR049. London: Department for Education.

ISER. (2002). National strategy for longitudinal studies. Essex: ISER.

Jenkins, S. (2008). Income and poverty: The rubber band theory. In R. Berthoud \& J. Burton (Eds.), Praise of panel surveys (pp. 2-3). Colchester: University of Essex.

King, L. A., \& Napa, C. K. (1998). What makes life good? Journal of Personality and Social Psychology, 75, 156-165.

Kroll, C., \& Delhey, J. (2013). A happy nation? Opportunities and challenges of using subjectiveindicators in policymaking. Social Indicators Research, 114(1), 13-28.

Land, K. C., Lamb, V. L., \& Mustillo, S. K. (2001). Child and youth well-being in the United States, 19751998: some findings from a new index. Social Indicators Research, 56, 241-320.

Lynn, P. (2003). Developing quality standards for cross-national survey research: five approaches. International Journal of Social Research Methodology, 4, 323-336.

Lynn, P. (2009). Methods for longitudinal surveys. In P. Lynn (Ed.), Methodology of longitudinal surveys (pp. 1-19). West Sussex: John Wiley and Sons Ltd.

Mason, J., \& Danby, S. (2011). Children as experts in their lives: child inclusive research. Child Indicators Research, 4, 185-189.

McGillivray, M. (2007). Human well-being: Issues, concepts and measures. In M. McGillivray (Ed.), Human well-being: Concept and measurement. Basingstoke: Palgrave MacMillan.

McGregor, I., \& Little, B. R. (1998). Personal projects, happiness, and meaning: on doing well and being yourself. Journal of Personality and Social Psychology, 74, 494-512. 
Montserrat, C., Dinisman, T., Bălțătescu, S., Grigoraș, B. A., \& Casas, F. (2014). The effect of critical changes and gender on adolescents' subjective well-being: Comparisons across 8 Countries. Child Indicators Research. Online First. http://ink.springer.com/article/10.1007\%2Fs12187-014-9288-9.

Moore, K. A., Murphey, D., Bandy, T., \& Lawner, E. (2014). Indices of child well-being and developmental contexts. In A. Ben-Arieh, F. Casas, I. Frones, \& J. E. Korbin (Eds.), Handbook of child well-being: Theories, methods and policies in global perspective (pp. 2807-2822). New York: Springer.

MYWEB (2014). Measuring youth well-being. European Commission funded project received funding under its 7 th framework programme. http://fp7-myweb.eu/.

Noll, H.-H. (2013). Subjective social indicators: benefits and limitations for policy making-An introduction to this special issue. Social Indicators Research, 114(1), 1-11.

OECD (2009). Doing better for children. http://www.oecd.org/social/family/doingbetterforchildren.htm. Accessed 16 Mar 2015.

Perrig-Chiello, P. (2009). Introduction. In P. Perrig-Chiello (Ed.), Changing childhood in a changing Europe (pp. 3-5). Strasbourg: Interdisciplinary Workshop Report. European Science Foundation.

Proctor, C. L., Linley, P. P., \& Maltby, J. (2009). Youth life satisfaction: a review of the literature. Journal of Happiness Studies, 10, 583-630.

Prout, A., \& James, A. (1997). Constructing and reconstructing childhood: Contemporary issues in the sociological study of childhood. London: UK Falmer Press.

Rees, G., \& Dinisman, T. (2014). Comparing children's experiences and evaluations of their lives in 11 different countries. Child Indicators Research. Online First. http://ink.springer.com/article/10.1007\% 2Fs12187-014-9291-1.

Rees, G., Bradshaw, J., Goswami, H., \& Keung, H. (2010a). Understanding children's well-being: A national survey of young people's well-being. London: The Children's Society.

Rees, G., Goswami, H., \& Bradshaw, J. (2010b). Developing an index of children's subjective well-being in England. London: The Children's Society. http://www.childrenssociety.org.uk/sites/default/files/tcs/ research_docs/Developing $\% 20$ an $\% 20$ Index $\% 20$ of $\% 20$ Children $\% 27 \mathrm{~s} \% 20$ Subjective $\% 20$ Well-being $\%$ $20 \mathrm{in} \% 20$ England.pdf.

Rees, G., Goswami, H., Pople, L., Bradshaw, J., Keung, A., \& Main, G. (2012). The good childhood report 2012: A review of our children's well-being. London: The Children's Society.

Rees, G., Goswami, H., Pople, L., Bradshaw, J., Keung, A., \& Main, G. (2013). The good childhood report 2013. London: The Children's Society.

Richardson, D. (2012). An evaluation of international surveys of children. Social Policy Division: OECD.

Ryan, R. M., \& Deci, E. L. (2001). On happiness and human potentials: a review of research on hedonic and eudaimonic well-being. Annual Review of Psychology, 52, 141-166.

Ryff, C. D., \& Keyes, C. L. M. (1995). The structure of psychological well-being revisited. Journal of Personality and Social Psychology, 69, 719-727.

Ryff, C. D., \& Singer, B. (1998). The contours of positive human health. Psychological Inquiry, 9, 1-28.

Ryff, C. D., \& Singer, B. (2000). Interpersonal flourishing: a positive health agenda for the new millennium. Personality and Social Psychology Review, 4, 30-44.

Sarriera, J. C., Casas, F., Bedin, L., Abs, D., Strelhow. M. R., Gross-Manos, D., \& Giger, J. (2014). Material resources and children's subjective well-being in eight countries. Child Indicators Research. Online First. http://link.springer.com/article/10.1007/s12187-014-9284-0.

Shadish, W. R., Cook, T. D., \& Campbell, D. T. (2002). Experimental and quasi-experimental designs for generalized causal inference. Boston: Houghton-Mifflin.

Shaw, C., Brady, L., \& Davey, C. (2011). Guidelines for research with children and young people. London: National Children's Bureau.

Social Protection Committee. (2012). Tackling and preventing child poverty, promoting child well-being. Brussels: Social Protection Committee Advisory Report to the European Commission.

TARKI Social Research Institute (2010). Child poverty and child well-being in the European Union. Report prepared for the DG Employment, Social Affairs and Equal Opportunities (Unit E.2) of the European Commission. Budapest: European Commission. Retrieved from http://www.tarki.hu/en/research/childpoverty/index.html.

The Children's Society. (2006). Good childhood? A question for our times. London: The Children's Society.

Thomas, W. I., \& Thomas, D. S. (1928). The child in America: Behaviour problems and programmes. New York: Knopf.

UNICEF. (2007). Child poverty in perspective: An overview of child well-being in rich countries. Innocenti Report Card 7. Florence: UNICEF Innocenti Research Centre. http://www.unicef-irc.org/publications/ pdf/rc7_eng.pdf. Accessed 6 Nov 2012. 
UNICEF. (2010). The children left behind: A league table of inequality in child well-being in the world's rich countries. Innocenti Report Card 9. Florence: UNICEF Innocenti Research Centre.

Veenhoven, R. (2002). Why social policy needs subjective indicators. Social Indicators Research, 58(1-3), 33-46.

Welsh Assembly Government (2008). Children and young people's well-being monitor for Wales. http://wales.gov.uk/docrepos/40382/40382313/293077/1266940/2765056/Monitor_Eng. pdf;jsessionid=8BA6FD345851E3B81C5540BD85F541D3?lang=en. Accessed 7 Nov 2012. 